\title{
Study on the Existence and Extent of Harassment among Medical Staff in a Saudi University Hospital
}

\author{
Khaldoon Aljerian', Arwa Almadani'2, Sara Saud Alharbi ${ }^{3}$ \\ ${ }^{1}$ Forensic Medicine Unit, Department of Pathology, College of Medicine, King Saud University, Riyadh, KSA \\ ${ }^{2}$ Department of Emergency Medicine, Ministry of National Guard Health Affairs, Riyadh, KSA \\ ${ }^{3}$ Department of Surgery, Ministry of National Guard Health Affairs, Riyadh, KSA \\ Email: khaldoonaljerian@gmail.com, Alamdani_ar@hotmail.com, Sara_s_alharbi@hotmail.com
}

How to cite this paper: Aljerian, K., Almadani, A. and Alharbi, S.S. (2017) Study on the Existence and Extent of Harassment among Medical Staff in a Saudi University Hospital. Open Journal of Social Sciences, 5, 45-55.

https://doi.org/10.4236/jss.2017.56006

Received: April 12, 2017

Accepted: June 12, 2017

Published: June 15, 2017

Copyright $\odot 2017$ by authors and Scientific Research Publishing Inc. This work is licensed under the Creative Commons Attribution International License (CC BY 4.0).

http://creativecommons.org/licenses/by/4.0/

\begin{abstract}
A questionnaire was distributed amongst staff to determine the existence and extent of harassment in the studied hospital. Harassment wasn't recognized as a problem by $45.8 \%$ of hospital staff. However, participants felt harassment was a serious issue. It is therefore recommended that substantial actions be taken to reduce harassment. A transparent, widely known, valid, readily accessible, and effective system for complaints is needed.
\end{abstract}

\section{Keywords}

Bioethics, Ethics, Medical, Harassment, Non-Sexual, Saudi Arabia, Sexual Harassment, Hospitals, University, Schools, Medical

\section{Introduction}

Harassment is "the act of systematic and/or continued unwanted and annoying actions of one party or a group, including threats and demands" [1]. Many publications studied harassment in healthcare [2]-[15]. Some focused on sexual harassment (SH) [2] [4]-[10] [12] [13] [14] [15]. A good number of studies specified nurses [2] [5] [7] [8] [12] [14] [15] and others residents [3] [6] [11]. A study conducted in Saudi Arabia at the National Guard hospitals showed 83.6\% reported one type of harassment amongst residents [3]. Physicians were the number one harassers in some studies [3] [4] [5] [6]; others showed that patients and their relatives accounted for the highest percentage [5] [7]. Many incidences of harassment go unreported. In an Australian study only 7\% of victims took a "formal action" by requesting an investigation by their organization, other res- 
pondents reported harassment, yet the majority did not believe sexual harassment was a problem at work [14]. The reasons given for not reporting incidences of harassment were clear amongst males, as they said they didn't need help dealing with the problem [10]. On the other hand, females gave a variety of reasons; most feared their reputation would suffer or felt guilty for the incidence itself. Multiple studies also showed that females did not report harassment due to the fear of revenge or job loss [10] [13]. The prevalence of harassment increased depending on age (those in their 20s and 30s were more at risk), marital status (with single female being at the highest risk) and the degree of qualification [5] [12].

This study aims to address harassment at a Saudi university hospital in general. The focus however, was on medical students, interns and residents in a Saudi university hospital, which makes this study unique. Harassment may be widely underestimated due to the social structure the conservative Saudi culture.

\section{Methods}

500 quantitative, cross sectional questionnaires (Appendix 1) were distributed amongst all residents in training, interns and 5th year medical students in the tertiary care unit of the university hospital. Prior to that, a pilot questionnaire was adapted after reviewing previous publications [1]-[15]. The pilot was distributed to 20 participants and the feedback was used to make slight modifications and ultimately tailor it to the target population. The threshold on whether harassment was deemed serious was set at the values specified in the study by Cogin, J. et al. (2002); when at least $60 \%$ of female staff and $34 \%$ of male staff report sexual harassment [8]. Of the 500 questionnaires, 233 were returned. Of these, 6 were discarded due to inconsistent answers leaving a total sample of 227. Of these 78 were from 5th year medical students, 72 from interns replied and 77 from residents. The age range was from 21 - 50 years old, with the mean being $25.31 \pm 3.236$. The first section of the questionnaire included consent, and a definition of harassment; this was to clarify that harassment is not restricted to sexual harassment. The remainder of the questionnaire comprised of 7 questions on demographics, 3 for knowledge of harassment, 8 for incidence, 5 on subsequent actions taken and results of these and lastly a question asking the participant to describe an episode in which they may have been involved. Data was then subject to qualitative analysis via correlation tests between incidence of harassment and the subject's age, gender, and specialty.

\section{Results}

Roughly, two thirds of participants (62\%) reported being a victim of harassment. Of these, $31 \%$ were sub-interns, $40.8 \%$ were interns, and $28.2 \%$ were residents (Table 1$)$. Gender played a significant role $(p=0.027)$ as $70.2 \%$ of cases were females. When correlating incidences to marital status, single participants had the highest percentage of harassment (74\%) followed by married individuals $(21.8 \%)$. The remaining groups (engaged and divorced) had insignificant com- 
Table 1. Details on the incidence of harassment. Inappropriate jokes were of greater concern for 5th year students and stalking had the highest incidence on interns. Regarding gender, almost all type of harassment was significantly higher for female subjects.

\begin{tabular}{|c|c|c|c|c|c|c|c|c|c|c|c|c|}
\hline \multirow{3}{*}{$\begin{array}{c}\text { Type of } \\
\text { Harassment }\end{array}$} & \multicolumn{6}{|c|}{ Position } & \multicolumn{5}{|c|}{ Gender } & \multirow{3}{*}{$p$-value } \\
\hline & \multicolumn{2}{|c|}{$5^{\text {th }}$ year students } & \multicolumn{2}{|c|}{ Interns } & \multicolumn{2}{|c|}{ Residents } & \multirow[t]{2}{*}{$p$-value } & \multicolumn{2}{|c|}{ Male } & \multicolumn{2}{|c|}{ Female } & \\
\hline & $\#$ & $\%$ & $\#$ & $\%$ & $\#$ & $\%$ & & $\#$ & $\%$ & $\#$ & $\%$ & \\
\hline $\begin{array}{c}\text { Inappropriate } \\
\text { jokes/comments }\end{array}$ & 37 & 84.1 & 37 & 63.8 & 27 & 67.5 & 0.021 & 46 & 68.7 & 55 & 75.3 & 0.103 \\
\hline $\begin{array}{l}\text { Inappropriate } \\
\text { gestures }\end{array}$ & 16 & 36.4 & 26 & 44.8 & 16 & 40.0 & 0.652 & 25 & 37.3 & 31 & 42.5 & 0.223 \\
\hline Verbal abuse & 12 & 27.3 & 17 & 29.3 & 15 & 37.5 & 0.225 & 28 & 41.8 & 16 & 21.9 & 0.012 \\
\hline $\begin{array}{c}\text { Racial } \\
\text { discrimination }\end{array}$ & 11 & 25.0 & 11 & 19.0 & 7 & 17.5 & 0.165 & 15 & 22.4 & 14 & 19.2 & 0.365 \\
\hline Stalking & 5 & 11.4 & 14 & 24.1 & 5 & 12.5 & 0.025 & 11 & 16.4 & 13 & 17.8 & 0.58 \\
\hline $\begin{array}{c}\text { Undesirable } \\
\text { physical } \\
\text { contact/unwanted } \\
\text { touch }\end{array}$ & 12 & 27.3 & 11 & 19.0 & 7 & 17.5 & 0.185 & 11 & 16.4 & 17 & 23.3 & 0.62 \\
\hline $\begin{array}{c}\text { Gender } \\
\text { discrimination }\end{array}$ & 0 & 0.0 & 1 & 1.7 & 1 & 2.5 & 0.822 & 1 & 1.5 & 1 & 1.4 & 0.65 \\
\hline $\begin{array}{l}\text { Bothersome } \\
\text { phone calls }\end{array}$ & 1 & 2.3 & 0 & 0.0 & 1 & 2.5 & 0.741 & 0 & 0.0 & 2 & 2.7 & 0.52 \\
\hline $\begin{array}{l}\text { Total any type } \\
\text { of harassment }\end{array}$ & & & & 58 & & 40 & - & & 57 & & 75 & - \\
\hline
\end{tabular}

plaints with $3.5 \%$ and $0.7 \%$ respectively. Age also had a significant effect on incidence, with $94.1 \%$ of sufferers being in their 20 s, $5.2 \%$ in their 30 s. Details of harassers are shown in Table 2 . Only $7.8 \%$ of people harassed logged an official complaint (11). The remaining $92.2 \%$ did not report officially. Of reported cases, an official action was taken in only 5; a warning letter was sent in 1 , a meeting with the administration was arranged in the second, and the contracts of the harassers were terminated in the remaining 2 cases. Of the 11 reported cases, 8 were in their 20s, 1 in their 30s and the remainder did not specify their age. In terms of gender, 7 were female and 4 male. When analyzing the reasons given to not report an incident of harassment, the most common was that it didn't adversely affect the harassed individual (Table 3). Analyzing the harassers, $8.1 \%$ of subjects admitted to having taken part in harassing someone. The most admitted form taken was inappropriate jokes and comments, with very few people admitting to any more serious actions (Table 4).

\section{Discussion}

As defined in the introduction, harassment may include all forms of unwanted attention or actions and is not restricted to undesired sexual advancements. Most studies conducted in the past looked at harassment in nurses, and focused on sexual harassment specifically. Our study is unique as it looked at a broader 
Table 2. Details on harassers according to gender and position. Most harassers were identified as males $(p<0.05)$ except amongst nurses where females were the main harassers.

\begin{tabular}{|c|c|c|c|c|c|c|c|}
\hline \multirow{2}{*}{ Harasser } & \multicolumn{2}{|c|}{ Male } & \multicolumn{2}{|c|}{ Female } & \multirow{2}{*}{$\begin{array}{l}\text { Unspecified } \\
\text { gender }\end{array}$} & \multirow{2}{*}{ Total } & \multirow[t]{2}{*}{$p$-value } \\
\hline & $\#$ & $\%$ & $\#$ & $\%$ & & & \\
\hline Student & 22 & 59.5 & 10 & 27.0 & 5 & 37 & 0.013 \\
\hline Intern & 12 & 46.2 & 10 & 38.5 & 4 & 26 & 0.225 \\
\hline Resident & 23 & 67.6 & 11 & 32.4 & 0 & 34 & 0.011 \\
\hline Team member & 13 & 65.0 & 5 & 25.0 & 2 & 20 & 0.0065 \\
\hline Patients & 36 & 66.7 & 10 & 18.5 & 8 & 54 & 0.001 \\
\hline Nurses & 3 & 17.6 & 11 & 64.7 & 3 & 17 & 0.001 \\
\hline Consultant & 54 & 66.7 & 13 & 16.0 & 14 & 81 & 0.012 \\
\hline Patient relatives and friends & 29 & 50.9 & 14 & 24.6 & 14 & 57 & 0.028 \\
\hline Administrative staff & 15 & 62.5 & 5 & 20.8 & 4 & 24 & 0.015 \\
\hline Laboratory staff & 2 & 100 & 0 & 0.0 & 0 & 2 & 0.001 \\
\hline Porter & 1 & 100 & 0 & 0.0 & 0 & 1 & - \\
\hline Unspecified position & 12 & 70.6 & 5 & 29.4 & 0 & 17 & 0.001 \\
\hline
\end{tabular}

Table 3. Reasons given for not reporting harassment.

\begin{tabular}{cccc}
\hline Reasons for not reporting & $\#$ & $\%$ & Ranking \\
\hline I felt ashamed & 9 & 7 & 6 \\
\hline Incidence didn't affect me/I saw no need to report & 69 & 53.1 & 1 \\
I feared the harasser's revenge & 15 & 11.5 & 5 \\
I didn't know what action to take & 39 & 30 & 2 \\
I thought it would make my work situation unpleasant & 29 & 22.3 & 3 \\
I thought it would be held against me or that I would be blamed & 27 & 20.8 & 4 \\
I did not want to hurt the person who bothered me & 15 & 11.5 & 5 \\
There was no security around & 1 & 1.9 & 8 \\
Thought no action would be taken & 2 & 3.7 & 7 \\
I told the harasser about the policy in the & & & \\
hospital and never saw him again & 1 & 1.9 & 8 \\
Thought it would affect my marks & 1 & 1.9 & 8 \\
The patient was elderly & 1 & 1.9 & 8
\end{tabular}

Table 4. Admitted forms of harassment by practicing individuals.

\begin{tabular}{cccc}
\hline Type of Harassment & $\#$ & $\%$ & Ranking \\
\hline Inappropriate jokes/comments & 17 & 44.7 & 1 \\
Inappropriate gestures & 4 & 10.5 & 3 \\
Verbal abuse & 9 & 23.7 & 2 \\
Racial discrimination & 2 & 5.3 & 4 \\
Stalking & 4 & 10.5 & 3 \\
Undesirable physical contact/unwanted touch & 2 & 5.3 & 4 \\
\hline
\end{tabular}


definition of harassment and across a myriad of academic levels and professional positions.

There is a higher prevalence of harassment than that acknowledged by the hospital community. $45.8 \%$ of participants stated that harassment was not a problem. While $62 \%$ said that they had been victims of harassment. This could be attributed by the sensitivity of this topic in Saudi Arabia in general. It is heavily influenced by conservative cultural norms and lack of transparency.

The frequency of harassment was lower than expected from the various literature reviews although it did exceed the stated threshold for concern. This is a problem of any study that is dependent on subjectivity. The results rely heavily on the definition used, the sample size and the particular group of people asked. One hospital reported over $75 \%$ harassment, but the sample size was merely 58 individuals [10]. Another reported over $83 \%$ but the sample size spanned 3 separate institutions [3] and one study reported $94 \%$ harassment, but they defined harassment as purely sexual [7]. It is therefore impossible to establish any definite objectivity on this subject and the results will vary widely.

The professional status of the individual showed to have a significant role in the frequency of reported harassment. Interns were the most likely to be harassed, followed by 5th year students and residents were found to be the least prone. This could be due to the interns' position at the bottom of the professional medical hierarchy, coupled with the highest hospital hours. Students in their 5th year (sub-interns) ranked second. Senior staff frequently tests them during rounds. Patients also frequently ask 5th year students for information. The discrepancies between the expectations of senior staff and patients on one hand and the actual knowledge level of students may contribute to a feeling of harassment. Residents were harassed the least, but made up a percentage that could not be overlooked (28.2\%). This may be because residents have a strong knowledge base and realize that the university hospital depend on them which gives them confidence.

Gender was also associated with the prevalence of harassment. Females were at a higher risk of being harassed than males. This could be due to the stereotype that put females at risk for being bothered generally and male prejudice that is embedded in society. Not surprisingly, these results were consistent with published literature.

When correlating age with the prevalence of harassment, most of our participants fell into the 20s and 30s group. A younger age showed an association with increased risk of harassment, as those in their 20s was more likely to be harassed than those in their 30s. Published literature draws a parallel result, as younger nurses were more likely to get harassed [11]. Additionally, younger individuals are more likely to report incidents whilst older individuals will dismiss considerable acts of harassment as childish behavior. Therefore, we must be careful not use an increased reporting of harassment in a specific harassed group, to compare to other harassed groups. Finally, single individuals were, at increased chances of being harassed. This correlates with most literature that single indi- 
viduals were more likely to be harassed [5] [12].

Finally, harassment is an existent and serious issue that needs to be tackled. The interpretation and reporting of harassment is subjective, therefore the results can never be used for an absolute conclusion on prevalence or for comparing harassed groups. Future studies may use an interview-based prospective study, to minimize subjectivity \& recall bias. Hospital policy on harassment should be transparent and enforced. Additionally, there should be significant steps to disseminate the policy using continuous repetitive seminars, multimedia, and on hospital screens in the hallways, waiting rooms \& lobbies, and hospital ward and office computers.

\section{Conclusion}

Harassment is an existent and serious issue. Although it is difficult to measure, there is a higher prevalence of harassment than recognized by the community in the studied hospital. An increased incidence of harassment was reported against interns and females. Younger age \& junior staff were at a higher risk. Policies on this matter, in all institutes, should be made clear with continuous education of all employees, students, patients and their relatives.

\section{Acknowledgements}

We would like to thank the College of Medicine Research Center (CMRC) for their support.

\section{References}

[1] Burton's Legal Thesaurus, 4E (2007) Harassment. http://legal-dictionary.thefreedictionary.com/harassment

[2] Bronner, G., Peretz, C. and Ehrenfeld, M. (2003) Sexual Harassment of Nurses and Nursing Students. Journal of Advanced Nursing, 42, 637-644. https://doi.org/10.1046/j.1365-2648.2003.02667.x

[3] Fnais, N., et al. (2013) Prevalence of Harassment and Discrimination among Residents in Three Training Hospitals in Saudi Arabia. Annals of Saudi Medicine, 33, 134-139. https://doi.org/10.5144/0256-4947.2013.134

[4] Shaikh, M.A. (2000) Sexual Harassment in Medical Profession-Perspective from Pakistan. JPMA. The Journal of the Pakistan Medical Association, 50, 130-131.

[5] Çelik, S.Ş., Celik, Y., Ağırbaş, İ. and Uğurluoğlu, Ö. (2007) Verbal and Physical Abuse against Nurses in Turkey. International Nursing Review, 54, 359-366. https://doi.org/10.1111/j.1466-7657.2007.00548.x

[6] Nagata-Kobayashi, S., Maeno, T., Yoshizu, M. and Shimbo, T. (2009) Universal Problems during Residency: Abuse and Harassment. Medical Education, 43, 628636. https://doi.org/10.1111/j.1365-2923.2009.03388.x

[7] Hibino, Y., Ogino, K. and Inagaki, M. (2006) Sexual Harassment of Female Nurses by Patients in Japan. Journal of Nursing Scholarship, 38, 400-405. https://doi.org/10.1111/j.1547-5069.2006.00134.x

[8] Cogin, J. and Fish, A. (2009) Sexual Harassment-A Touchy Subject for Nurses. Journal of Health Organization and Management, 23, 442-462.

https://doi.org/10.1108/14777260910979326 
[9] Kinard, J. and Little, B. (2002) Sexual Harassment in the Health Care Industry: A Follow-Up Inquiry. The Health Care Manager, 20, 46-52. https://doi.org/10.1097/00126450-200206000-00008

[10] Komaromy, M., Bindman, A.B., Haber, R.J. and Sande, M.A. (1993) Sexual Harassment in Medical Training. New England Journal of Medicine, 328, 322-326. https://doi.org/10.1056/NEJM199302043280507

[11] Ogunsemi, O.O., Alebiosu, O.C. and Shorunmu, O.T. (2010) A Survey of Perceived Stress, Intimidation, Harassment and Well-Being of Resident Doctors in a Nigerian Teaching Hospital. Nigerian Journal of Clinical Practice, 13, 183-186.

[12] Hibino, Y., Hitomi, Y., Kambayashi, Y. and Nakamura, H. (2009) Exploring Factors Associated with the Incidence of Sexual Harassment of Hospital Nurses by Patients. Journal of Nursing Scholarship, 41, 124-131. https://doi.org/10.1111/j.1547-5069.2009.01244.x

[13] Chaudhuri, P. (2007) Experiences of Sexual Harassment of Women Health Workers in Four Hospitals in Kolkata, India. Reproductive Health Matters, 15, 221-229. https://doi.org/10.1016/S0968-8080(07)30319-4

[14] Madison, J. (1997) Australian Registered Nurses Describe the Health Care Workplace and Its Responsiveness to Sexual Harassment. Australian Health Review, 20, 102-115. https://doi.org/10.1071/AH970102

[15] Kisa, A. and Dziegielewski, S.F. (1996) Sexual Harassment of Female Nurses in a Hospital in Turkey. Health Services Management Research, 9, 243-253.

https://doi.org/10.1177/095148489600900404 


\section{Appendix}

We are researchers who would like to assess the existence and extent of harassment in sub-interns, interns and residents at King Khalid University Hospital (KKUH). The KSU IRB has approved our study. We would like to assure that all the information will be handled confidentially. Your participation is much appreciated. Your participation is voluntary, and you may withdraw at any time. Harassment is the act of systematic and/or continued unwanted and annoying actions of one party or a group, including threats and demands. Examples of harassment:

$\begin{array}{ll}\text { 1. Inappropriate jokes/comments } & \begin{array}{l}\text { 2. Inappropriate gestures } \\ \text { (e.g. winking, flying kiss, inappropriate gazing/looking) }\end{array} \\ \begin{array}{ll}\text { 3. Verbal abuse } & \text { Racial discrimination } \\ \text { 5. Stalking } & \text { 6. Undesirable physical contact/unwanted touch } \\ \text { 7. Sexual behaviors } & \end{array}\end{array}$

If you would like to participate, please sign:

Signature of the participant:

Name of the researcher:

Serial number (by the researcher):

(1) Position:

a) Sub-intern $/ 5^{\text {th }}$ year student

b) Intern

c) Resident

d) R1

e) R2

f) R3

g) $\mathrm{R} 4$

h) $R 5$

i) R6

j) Other

(2) Years of employment: year/s

(3) Gender:

a) Male

b) Female

(4) Age: years

(5) Residency/Postgraduate program:

\begin{tabular}{llll}
\hline o & Anatomy & 0 & Anesthesia \\
0 & Biochemistry & 0 & Emergency Medicine \\
0 & ENT & 0 & Family and Community Medicine \\
o & Internal Medicine & o & Microbiology \\
o & Obstetrics and Gynecology & 0 & Ophthalmology \\
0 & Orthopedics & 0 & Pathology \\
0 & Pediatrics & 0 & Pharmacology \\
0 & Physiology & 0 & Psychiatry \\
0 & Radiology & 0 & Surgery \\
0 & N/A & 0 & Other: \\
\hline
\end{tabular}


(6) Sponsor:

(7) Marital status:

\begin{tabular}{llll}
\hline 0 & Divorced & 0 & Engaged \\
0 & Married & 0 & Single \\
0 & Widowed & 0 & Other: \\
\hline
\end{tabular}

(8) Do you think harassment (as defined above) is a problem in King Khalid University Hospital (KKUH)?

\begin{tabular}{llll}
\hline o & Yes & No & No \\
0 & I do not know & & \\
\hline
\end{tabular}

(9) Have you ever been bothered by any of the following? (you may choose more than one)

\begin{tabular}{llll}
\hline o Inappropriate jokes/comments & $\begin{array}{l}\text { o Inappropriate gestures } \\
\text { (e.g. winking, flying kiss, inappropriate gazing/looking) }\end{array}$ \\
o & Verbal abuse & o & Racial discrimination \\
o & Stalking & o & Undesirable physical contact/unwanted touch \\
o & No (if "NO", please go to 17 ) & o & Other: \\
\hline
\end{tabular}

(10) Who was the harasser? Tick the box and circle the gender you may choose more than one)

$\begin{array}{ll}\text { o Student (Male/Female) } & \text { o Intern (Male/Female) } \\ \text { o Resident (Male/Female) } & \text { o } \text { Team member (Male/Female) } \\ \text { o Patient (Male/Female) } & \text { o Nurses (Male/Female) } \\ \text { o Consultant (Male/Female) } & \text { o Patient relatives and friends (Male/Female) } \\ \text { o Administrative staff (Male/Female) } & \text { o Don't know or "random person" (Male/Female) } \\ \text { o Other:__(Male/Female) } & \end{array}$

(11) At what time was the harassment? ( you may choose more than one)

$\begin{array}{llll}0 & \text { Morning }(7 \mathrm{am}-3 \mathrm{pm}) & \text { o } & \text { Afternoon }(3 \mathrm{pm}-11 \mathrm{pm}) \\ 0 & \text { Night. }(11 \mathrm{pm}-7 \mathrm{am}) & & \end{array}$

(12) What was your response? (you may choose more than one)

o Reported an official complaint (please answer questions 13\&14, then skip 15)

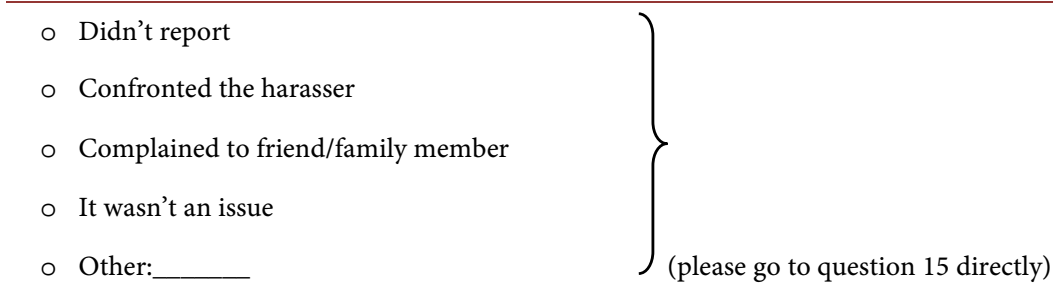


(13) After reporting, was an official action taken?

o Yes, what type of action?

o No

o Not applicable

(14) After reporting, what did the harasser do?
o Stop bothering you
o Continue to bother you
o Bothered you more than before
o Not applicable
o Other

(15) If you did not report, why didn't you report (you may choose more than one)?
o I felt ashamed
o The incidence didn't affect
o I fear the Harasser revenge me/I saw no need to report it
o I thought it would make my work situation unpleasant
o I did not know what action to take
o I thought it would be held
o I did not want to hurt the person
who bothered me against me or that I would be blamed
o Other:
o Not applicable

(16) How were you affected by the incidence? (you may choose more than one)

\begin{tabular}{lll}
\hline o Shame & o Anger & o Guilt \\
o Affected my social life negatively & o Wasn't affected & o Humiliation \\
o Affected my work performance negatively & o Other: & \\
\hline
\end{tabular}

(17) Do you know any one that has been harassed?

o Yes

o No

(18) Does your organization have a formal policy for dealing with harassment?

o Yes

o No

o I don't know

(19) Would you like the policy of complaints to be distributed and well known to KKUH attendants?

o Yes

o No

o I don't care

(20) Did you ever harass any one?

o Yes (If you answered "YES", please answer the questions 21 - 23 also)

o No (If you answered "NO", please go to question 24 directly) 
(21) How did you harass them? (you may choose more than one)

\begin{tabular}{ll}
\hline o Inappropriate jokes/comments & $\begin{array}{l}\text { o Inappropriate gestures } \\
\text { (winking, flying kiss, inappropriate gazing/looking) }\end{array}$ \\
o Verbal abuse & 0 Racial discrimination \\
o Stalking & o Undesirable physical contact/unwanted touch \\
o Other: & \\
\hline
\end{tabular}

(22) Why did you do it?
o Position authority
o Amusement
o Sarcasm
o Other:

(23) Whom did you harass? Choose both position and gender (you may choose more than one)
o Student (Male/female)
o Intern ( Male/female )
o Resident (Male/female)
o Team member ( Male/female )
o Patient (Male/female)
o Nurses ( Male/female)
o Consultant (Male/female)
o Patient relatives and friends ( Male/female )
o Administration (Male/female)
o Don't know "random person” ( Male/female)
o Other:
(Male/female)

(24) If you would like to share an experience or a story, please fill below:

Submit or recommend next manuscript to SCIRP and we will provide best service for you:

Accepting pre-submission inquiries through Email, Facebook, LinkedIn, Twitter, etc. A wide selection of journals (inclusive of 9 subjects, more than 200 journals)

Providing 24-hour high-quality service

User-friendly online submission system

Fair and swift peer-review system

Efficient typesetting and proofreading procedure

Display of the result of downloads and visits, as well as the number of cited articles Maximum dissemination of your research work

Submit your manuscript at: http://papersubmission.scirp.org/

Or contact jss@scirp.org 